\title{
Maio-Junho de 1968 na França O EPICENTRO DE UMA CRISE DE HEGEMONIA (PARTE II) ${ }^{1}$
}

\author{
Alain Bihr ${ }^{2}$
}

\section{Resumo}

Neste artigo, o autor reexamina a história de um ciclo de lutas sociais, políticas e culturais como epicentro da crise de hegemonia. Na base das principais radicalizações políticas estudantis, operárias e dos novos movimentos sociais do maio-junho de 1968, ainda estão as lutas de classes, com tudo o que têm de indeterminado a priori, na medida em que resultam da evolução das correlações de forças cujos protagonistas não podem dominar ou prever. Se, em tal história, tudo não é possível, também nada é escrito com antecedência. Conseqüentemente, não era necessário que esta história terminasse como (provisoriamente) se concluiu. $\mathrm{Na}$ França, como em outros lugares, a História continua.

Palavras-chave: Hegemonia. Lutas proletárias. Classes sociais.

\begin{abstract}
The author reexamines a cycle of social, political and cultural struggles that evidenced a crisis of hegemony and whose epicenter occurred in May and June of 1968. At their base, the principle political radicalizations of students, workers

\footnotetext{
${ }^{1}$ Tradução de Fátima Murad. Revisão técnica de Renata Gonçalves e Sávio Cavalcante. "grande noite" à alternativa. São Paulo, Boitempo Editorial, 1998.
}

${ }^{2}$ Professor de sociologia da Université Franche-Comté; autor de vários livros, dentre os quais $D a$
\end{abstract}


and new social movements in that year are class struggles, with all that implies in terms of a priori indeterminacy, to the extent that they result from the evolution of the balance of forces that their protagonists cannot control or foresee. If, in that story, not everything is possible, nothing is determined ahead of time, either. Therefore, it was not necessary for this story to end as it (provisionally) concluded. In France, as in other places, history goes on.

Keywords: Hegemony. Proletarian struggles. Student Movement.

\section{A LONGA MARCHA DO ENQUADRAMENTO ${ }^{3}$ RUMO AO PODER: DA “CONTESTAÇÃO” À “SUBMISSÃO VOLUNTÁRIA"}

Omo tive oportunidade de mencionar mais acima, a crise latente de hegemonia que a França vive nos anos de 1960 sob a aparência de um regime gaullista sólido, e que vai eclodir em maio-junho de 1968, compreende ainda uma segunda dimensão. É que, assim como o proletariado, a antiga fórmula hegemônica fundada na aliança da grande burguesia industrial e financeira com as classes médias tradicionais marginaliza politicamente a classe do enquadramento, que agrupa o que se costuma denominar "camadas médias assalariadas". E assim como o proletariado, mas por razões em parte diferentes, o enquadramento encontrará na dinâmica do regime fordista matéria para se revoltar contra essa marginalização. É isso, principalmente, que explica a presença na eclosão de maio-junho de 1968 e em seus desdobramentos desse segundo componente da contestação, cuja ponta de lança será, ao longo desses anos, o movimento estudantil. Porém, a resolução dessa crise de hegemonia reservará um destino diferente a esse componente: ela se tornará um elemento decisivo da nova fórmula hegemônica. É esse processo que se propõe analisar a última parte de meu artigo ${ }^{4}$.

\footnotetext{
${ }^{3}$ N. R.: Em francês, encadrement é o nível em que se encontram os assalariados superiores responsáveis pela gestão das empresas e aparelhos do Estado.

${ }^{4}$ Mais do que as diferenças de natureza e de destino desses dois protagonistas do movimento de maio-junho de 1968, foram as exigências próprias à análise desse movimento que me levaram a examiná-lo à parte neste artigo. Na realidade, os dois componentes não deixaram de interagir, como espero ter mostrado.
} 


\section{AS RAZÕES DA RADICALIZAÇÃO POLÍTICA DO ENQUADRAMENTO}

0 regime fordista de reprodução do capital vai reforçar enormemente o peso do enquadramento na formação social francesa ao longo dos anos 1950 e 1960. Primeiro, seu peso demográfico. Entre 1954 e 1975, os efetivos do enquadramento aumentaram 2,6 vezes, passando de 8\% para mais de 12\% da população ativa. Seu crescimento absoluto e relativo contrasta assim com o declínio paralelo das classes médias tradicionais mencionado anteriormente. Durante esse período, o enquadramento acolherá em suas fileiras um grande número de filhos de operários, de camponeses, de pequenos comerciantes para os quais a democratização do ensino médio abre perspectivas de ascensão social.

Esse fortalecimento demográfico do enquadramento é acompanhado de um fortalecimento socioeconômico: é sobre ele, e principalmente sobre as camadas e categorias geradas especificamente pelo fordismo, tanto no setor público (os aparelhos de Estado e as empresas estatais) como no setor privado (as empresas capitalistas), que se apoiará a modernização capitalista da França ao longo dessas duas décadas. Para dar apenas dois exemplos, nas empresas, os engenheiros, técnicos e agentes de pessoal é que serão ao mesmo tempo os agentes e os beneficiários (em termos de renda, poder e prestígio) da implantação da "organização científica do trabalho", em outras palavras, das formas especificamente fordistas de dominação e de exploração do trabalho proletário: elas promoverão a figura do quadro (superior e médio) como a figura central da economia fordista 5 . Enquanto que caberá aos professores, da escola primária até a universidade, e, mais especificamente, os do ensino médio, a tarefa de formar as gerações de quadros, mas também de operários e de empregados qualificados dos quais o fordismo necessitará em todos os seus aspectos e em todos os setores da vida econômica, social, administrativa, cultural, etc.

Enfim, os valores (de modernização, de racionalização, de democratização) de que o fordismo é portador, implicitamente ou muitas vezes até explicitamente, são justamente os do enquadramento (BIHR, 1989, p. 251-269). Isso só faz consolidar ainda mais essa classe no plano ideológico, reforçando sua legitimidade (de sua situação, de seus interesses, de suas aspirações, etc.) aos seus próprios olhos e aos olhos dos membros das outras classes. Isso se traduz principalmente na aparição e no desenvolvimento ao longo desse período de toda uma imprensa semanal dirigida a essa classe e que promove seus valores: L'Express (1953), Le

${ }^{5} \mathrm{Cf}$. a esse respeito Boltanski (1982), capítulo II.

Maio-junho de 1968 na França. O epicentro de uma CRISE ... 
Nouvel Observateur (1964) Le Point (1972), e o Le Monde, que é na época a contrapartida na imprensa diária.

Nessas condições, pode parecer surpreendente que setores inteiros do enquadramento também tenham radicalizado no plano político durante os anos 1960, a ponto de sair às ruas e montar barricadas, em suma, de participar da revolta de maio-junho de 1968, assim como de seus desdobramentos. É que, a despeito do que foi dito anteriormente, o enquadramento em geral e suas gerações mais jovens em particular - aquelas nascidas no pós-guerra e que vão fazer parte do mundo estudantil nos anos 1960 - não encontrarão um lugar dentro da sociedade francesa da época. $0 \mathrm{u}$, pelo menos, o lugar que essa sociedade lhe reserva então não se ajusta inteiramente, ou se ajusta mal, aos seus interesses, aspirações ou ambições. E isso tem a ver, diretamente ou indiretamente, com a existência da aliança hegemônica selada pelo regime gaullista.

Esta se revela, em primeiro lugar, no plano sociopolítico. É que, como já tive oportunidade de assinalar, desde suas origens, a aliança entre a grande burguesia e as classes médias tradicionais tende a marginalizar politicamente 0 enquadramento, afastando suas organizações politicamente representativas (a SFI0 ${ }^{6}$ e o PC) do primeiro plano no cenário político (o cenário parlamentar e governamental, com seus prolongamentos eleitorais e midiáticos). Em suma, só 0 autoriza a desempenhar o papel de classe de apoio da aliança hegemônica lá onde seu peso socioeconômico e cultural crescente lhe permite entrever a possibilidade de ascender à posição de classe reinante. E justamente o que ocorre, na mesma época, em vários Estados do norte da Europa via os partidos social-democratas, 0 que torna tanto mais anacrônica e insustentável a situação do enquadramento na França. Observa-se mais uma vez aqui a contradição interna ao regime gaullista, já apontada acima, entre a base sociopolítica (a antiga aliança hegemônica) que marginaliza o enquadramento e a base socioeconômica (a dinâmica fordista) que, ao contrário, tende a transformar o enquadramento em um ator chave.

Uma contradição análoga aparece, em segundo lugar, no nível sociocultural, de maneira ainda mais aguda. Como já disse, o enquadramento é portador, na França dos anos 1960, dos valores da modernidade fordista tal como se expressam na reorganização do trabalho e da produção. Mas é igualmente portador dos valores difundidos por essa mesma modernidade fora do trabalho que, como vimos mais acima, se condensam em formas de socialização que exigem e ao mesmo

${ }^{6}$ N. R.: Seção Francesa da Internacional Operária. 
tempo exaltam uma autonomia individual ampliada e reforçada. Contudo, na França dos anos 1960, por meio da antiga aliança hegemônica, a esfera pública ainda é amplamente dominada pelos valores e as normas éticas, morais, políticas e religiosas defendidos pelas classes médias tradicionais. Valores que exaltam 0 amor ao trabalho (de tipo artesanal) bem realizado, a pequena propriedade privada acumulada ao final de uma vida de trabalho, a família dominada pela figura do pai autoritário, quando não despótico, ao qual são estritamente subordinados a esposa e os filhos, a obediência à autoridade em geral, uma moral rigorista feita de frugalidade, de repressão da sexualidade fora do casamento, um patriotismo extremamente chauvinista resvalando facilmente para o racismo, etc. E, acima de tudo, a desconfiança em relação a qualquer mudança. Nem era necessário raspar muito o verniz republicano da vida pública sob o regime gaullista para encontrar ali o lema de Pétain "Trabalho, familia, pátria". Para ser breve, vou me limitar a alguns exemplos. É apenas em 1965 que as mulheres casadas obtêm o direito de exercer uma atividade profissional sem autorização do marido. Em 1966, sob pressão do lobby das associações católicas, André Malraux proíbe a adaptação de Jacques Rivette para o cinema do romance de Diderot, $A$ religiosa, considerado anticlerical. E a autorização de colocar no mercado a pílula anticoncepcional, votada pelo Parlamento em 1967, terá de aguardar ainda entre quatro e sete anos os decretos de aplicação, e portanto ficará adiada pelo mesmo tempo. Nem é preciso insistir mais sobre a aversão de várias camadas e categorias do enquadramento ao universo cultural dominado pelo autoritarismo e o moralismo, sob a figura tutelar do pai gaullista.

Como sugerem, aliás, os exemplos anteriores, a contradição entre os valores de modernidade e de autonomia individual promovidos pelo enquadramento e os valores das classes médias tradicionais éparticularmente acentuada em dois planos: o das relações entre as gerações (entre pais e filhos, entre professores e alunos) e o das relações entre gêneros (mulheres e homens). Assim, ela se reflete principalmente nas duas principais instituições no interior das quais essas relações se reproduzem e se articulam: a família e a escola - duas instituições em plena transformação na época, sob o efeito da dinâmica fordista que exige um direcionamento em massa das mulheres para a atividade profissional (assalariada) e uma 'democratização' (muito relativa) do ensino médio e superior. Já se vê aqui o esboço de algumas linhas de fratura ideológica, de eixos de contestação e de reivindicação política, de terrenos e de focos de lutas que se revelarão quando da revolta de certos elementos do enquadramento em maio-junho de 1968 e nos anos seguintes. 
Para concluir a explanação do pano de fundo da revolta, devemos observar que essas contradições serão exacerbadas entre as gerações mais jovens do enquadramento. De um lado, porque na época eles se reconheciam menos ainda que os mais velhos nos representantes políticos (organizações e homens) tradicionais de sua classe: a SFIO, pelo envolvimento nas guerras coloniais e 0 apoio ao gaullismo, e o PC, em razão do caráter stalinista persistente. Em outras palavras, nos anos 1960, essas gerações estão órfãs de representantes e buscam novas mediações e referências políticas. De outro lado, mais do que as gerações anteriores, elas se sentem sufocadas pela "ordem moral" mantida pela aliança hegemônica, pois se encontram no cruzamento das relações entre gerações e das relações entre gêneros (estão na "entrada na vida" que é também a entrada na sexualidade adulta), ou seja, no epicentro das contradições que marcam a modernização fordista da sociedade francesa. Finalmente, entre essas jovens gerações, a parcela de auto-reprodução da classe (comparativamente à parcela dos membros oriundos por mobilização social ascendente ou descendente das classes populares ou das classes superiores) já é, sem dúvida, bastante significativa para provocar nela um fenômeno semelhante ao que se observava no mesmo momento na juventude operária: as pessoas já não se contentam mais com a aquisição média a que o fordismo dá direito em sua classe, elas querem mais!

\section{AS DIFERENTES VIAS E FORMAS DA RADICALIZAÇÃO POLÍTICA DO ENQUADRAMENTO}

0 conjunto de todos esses elementos explica, no essencial, a radicalização política de parte dos membros do enquadramento no final dos 1960 e inícios dos anos 1970, paralelamente e em sinergia com a ofensiva operária analisada antes, em que os dois movimentos se completam e se reforçam mutuamente antes de se divorciarem na continuidade. Do mesmo modo que as próprias lutas operárias, essa radicalização mostrará diferentes rostos: múltiplos atores, formas de mobilização, terrenos de luta e, evidentemente, objetivos e resultados diferentes.

Mais uma vez, para clareza da exposição, é preciso distingui-los com nitidez e examiná-los separadamente, ou pelo menos sucessivamente. Na medida em que, na realidade, os atores se misturaram uns aos outros, o movimento geral fundia mobilizações diversas, passava-se de um terreno de luta a outro, e os resultados só foram distinguidos e hierarquizados de forma muito progressiva. Ordenarei a exposição indo dos elementos mais radicais do movimento aos elementos mais moderados - que serão também os que vão ter maior relevância histórica. 
1. O movimento universitário, que rapidamente se estendeu aos colégios, constituirá o núcleo duro, o centro ativo e o principal motor da radicalização política do enquadramento. De fato, sua politização precede a irrupção da primavera de 1968: ela vem das mobilizações contra a guerra da Argélia (que termina em 1962), depois contra a intervenção dos Estados Unidos no Vietnam. E, assim como as lutas operárias, prosseguirá até a segunda metade da década seguinte: em 1973, é um vasto movimento contra uma reforma do serviço militar, seguido em 1976 de uma mobilização contra a reforma do segundo ciclo do ensino superior.

Tratando-se de uma mobilização da classe do enquadramento, essa centralidade do movimento estudantil não surpreende a priori. De fato, a melhor via de acesso (se não a única) a uma posição socioprofissional que garanta o pertencimento a essa classe passa pela obtenção de diplomas escolares, principalmente universitários, pelo menos para todos aqueles e aquelas oriundos dessa mesma classe e a fortiori para os filhos das classes populares (agricultores, artesãos e pequenos comerciantes, operários) em fase de mobilização social ascendente. Como aparelho que garante a formação e a qualificação diferenciais da força de trabalho e, portanto a reprodução da divisão técnica e sobretudo social do trabalho, a escola (incluída a universidade) é o aparelho de Estado no qual se concentra a reprodução do enquadramento como classe social, compreendida sua diversidade e sua hierarquia internas; inversamente, no que se refere às classes populares (em particular o proletariado), a escola funciona como desqualificação e exclusão. Portanto, ela é também o aparelho no interior do qual os membros dessa classe se socializam especificamente, e onde adquirem, confirmam e sobretudo legitimam a maior parte das propriedades objetivas (no caso os títulos escolares) e subjetivas (as disposições, o babitus) próprias à sua classe. Assim, qualquer radicalização das gerações mais jovens do enquadramento sempre encontrará no aparelho escolar seu principal lugar de expressão e ponto de apoio, seu crisol, de certo modo; e, inversamente, qualquer movimento que surja no âmbito desse aparelho (movimento secundarista ou universitário) será sempre dominado pelos elementos do enquadramento.

Esse elemento estrutural que determina a centralidade do movimento estudantil na radicalização do enquadramento será reforçado, em pleno auge dos anos 1960, por alguns fatores próprios à dinâmica fordista já mencionados anteriormente. De um lado, está o inchamento da população universitária e secundarista, graças à 'democratização' do ensino que a modernidade fordista tornou necessária, aspecto particular do crescimento demográfico absoluto e 
relativo do enquadramento de que essa modernidade é portadora. De outro lado, vimos que a escola, ao lado da família, é uma das instituições mais afetadas pelo reflexo no interior das relações intergeracionais da contradição entre os valores da modernidade fordista difundidos pelo enquadramento e a persistência do universo moral tradicional ligada à antiga aliança hegemônica: 0 modo autoritário da relação com o saber e das relações pedagógicas constituirá um dos alvos imediatos do movimento universitário e secundarista. Por último, a aspiração e a exigência de uma maior autonomia individual, que resultam de formas fordistas de socialização dos indivíduos, paradoxalmente ganharão força e se legitimarão no conteúdo do ensino escolar e universitário ainda em vigor nos anos 1960, dominado pelas humanidades, e, portanto, pela herança do humanismo e do Iluminismo. Os acentos de radicalidade da burguesia, apegada aos privilégios da aristocracia e ao obscurantismo da religião enquanto era ainda somente uma classe lutando para chegar ao poder, apesar de já existir há vários séculos, ressurgirão no espírito e mesmo na letra de algumas das reivindicações e dos slogans estudantis de maio-junho de 1968. Assim, para ficar apenas nesse exemplo, todas as reivindicações e experiências de relações pedagógicas não autoritárias e de práticas pedagógicas não diretivas, efeitos mais imediatos do movimento universitário e secundarista, encontram suas raízes, via os pedagogos da Escola Nova do fim do século XIX e início do século XX (Montessori, Claparède, Dewey, Freinet, Decroly, Makarenko), nos princípios expostos por Jean-Jacques Rousseau em seu Emilio (1762).

Essa centralidade do movimento estudantil tem a ver, finalmente, com a presença nele de grupos e organizações 'esquerdistas já mencionados e, em menor proporção (pois sua platéia era mais reduzida), de grupos conselhistas, anarquistas ou situacionistas. Pois será essencialmente no mundo universitário e secundarista que esses grupos e organizações vão recrutar adeptos ao longo desses anos. É, de fato, através deles que, de um lado, grande parte do movimento estudantil se impregnará de conceitos e teorias, objetivos políticos e palavras de ordem de um marxismo em geral muito sumário que, a despeito de seus limites manifestos, não deixou de contribuir para sua radicalização política; e que, de outro lado, também através desses grupos 'esquerdistas, o movimento estudantil procurará se articular, efetiva e simbolicamente, com as lutas operárias - sem, contudo, conseguir verdadeiramente, graças à eficácia do cordão sanitário estendido pela CGT e pelo PC para evitar que o mundo operário fosse contaminado pelo vírus "esquerdista". 
2. A partir desse pólo de radicalidade constituído pelo movimento universitário e secundarista ao longo desses anos, a revolta do enquadramento se difundiu pelo campo social, não só por mero efeito de contágio, mas também pela migração para esse campo de agentes do enquadramento que tinham passado antes pela escola da contestação que foi a universidade. Assim, ele fez parte da eclosão e do desenvolvimento daquilo que, a partir de Alain Touraine, será chamado de "novos movimentos sociais".

Os principais, aqueles que permanecerão mais tempo e que produzirão os efeitos mais importantes e mais duradouros em termos de transformação de práticas e representações sociais e de relações sociais, foram o movimento feminista (mobilizado principalmente pelo direito à contracepção e à legalização do aborto) e os movimentos em favor do reconhecimento da identidade homossexual, os movimentos ecologista (que ganha projeção principalmente com a candidatura de René Dumont à eleição presidencial de 1974) e antinuclear (este último, sobretudo na segunda metade dos anos 1970, quando o governo inicia um amplo programa de construção de centrais nucleares), os movimentos antimilitaristas (com a formação de comitês de soldados) e pacifista (prolongando o movimento bippie), os movimentos regionalistas e nacionalistas (na Alsácia, na Bretanha, na Córsega, no Languedoc, no País Basco). Mas se assistirá também à eclosão e ao desenvolvimento de movimentos de ação urbana (comitês de bairros, comitês de usuários de transportes coletivos) contestando os efeitos do urbanismo funcionalista, dos movimentos contra o encarceramento (movimento de detentos e de apoio aos detentos), movimentos de experimentação de outras instituições médicas e de outras terapêuticas (tanto no campo da medicina geral como da psiquiatria), movimentos de experimentação de outras práticas conjugais e familiares (as comunidades), as transmissões das primeiras rádios piratas, etc. E se assistirá até mesmo, na primavera de 1975, a uma efêmera mobilização das prostitutas contra a repressão policial e judicial da prostituição.

\footnotetext{
${ }^{7}$ Essa denominação foi proposta na segunda metade dos anos 1970 par Alain Touraine e sua escola sociológica (Dubet, Wieviorka). As duas obras fundadoras dessa abordagem foram La société postindustrielle (1969) e La voix et le regard (1978). Essa denominação acabou por se impor, razão pela qual eu a retomo aqui, mas sem compartilhar absolutamente as interpretações dadas a esses movimentos pela escola tourainiana. Propus uma análise alternativa em Bihr (1991, capítulo VIII), da qual retomarei aqui apenas alguns elementos e à qual remeto aqueles que desejarem aprofundar a análise.
} 
Para além de sua heterogeneidade, que desde o início foi um obstáculo à sua unificação, mesmo na forma federativa, esses movimentos tinham, no entanto, alguns traços comuns. Em primeiro lugar, seus terrenos de mobilização e seus objetivos de luta se situavam todos fora da esfera do trabalho e da produção, ainda que tivessem alguma relação com essa esfera. De fato, embora nem sempre tivesse clara consciência disso, eles expressavam as tensões e contradições nascidas da ampliação e do aprofundamento da ascendência capitalista sobre o conjunto das condições sociais de existência, cada vez mais estreitamente subordinadas às exigências da reprodução do capital. Em particular, todas aquelas que, como já disse antes, levam à exacerbação do desejo de individualização - desejo cuja presença será mais patente nos movimentos feminista ou de reivindicação homossexual - e que conduzem logicamente à contestação dos aparelhos mais autoritários: ao lado da fábrica, da família, da escola, do exército, da prisão, do hospital psiquiátrico, etc.

Em segundo lugar, esses movimentos se caracterizavam justamente pela predominância em seu interior da influência do enquadramento capitalista. É que, por sua situação dentro das relações de produção, os membros dessa classe são menos duramente submetidos à exploração e à dominação capitalistas no trabalho (mesmo constituindo seus agentes subalternos) do que os proletários ou as camadas populares em geral. Mas, ao mesmo tempo, são mais sensíveis às tensões e contradições que provoca a dominação capitalista sobre a sociedade fora do trabalho, às degradações das condições de existência que podem resultar daí, como também às novas possibilidades (às novas práticas sociais, às novas formas de existência individuais e coletivas) para as quais inversamente abrem caminho.

Em terceiro lugar, nas práticas sociais e políticas que desenvolveram, todos esses movimentos se caracterizaram por dois traços ao mesmo tempo opostos e complementares: de um lado, uma ação crítica e contestadora, pondo em questão de maneira mais ou menos radical um aspecto particular das condições sociais de existência resultante de sua apropriação capitalista, de sua subordinação às exigências gerais da reprodução do capital, acusando os diversos poderes civis e políticos inspiradores dessa apropriação; e, de outro lado, uma vontade pragmática de reapropriação imediata dessas mesmas condições de existência, trazendo em seu rastro uma floração de "contra-poderes" e de "práticas alternativas" experimentando as vias mais diversas que conduzissem ou que se suponha que conduziriam a tal reapropriação, incluídas as mais diretas e as mais transgressivas. 
Em quarto e último lugar, esses movimentos sociais se declaravam em geral portadores de uma nova cultura política centrada no conceito de autogestão e, mais amplamente, de novas exigências e valores éticos expressados por toda uma série de slogans e de palavras de ordem que lhes serviram de língua comum: "experimentação social", "viver de maneira diferente", "a qualidade de vida", "a convivência, "o direito à diferença", etc. Assim, esses movimentos elaboraram e difundiram uma cultura bastante antiestatizante e, de maneira geral, antiautoritária - fazendo eco às tendências correspondentes em certas lutas operárias ou em certas dimensões dessas lutas, como já tive oportunidade de mostrar antes.

Contudo, a despeito dessa afinidade, o conjunto das características anteriores tornava de fato os diversos "novos movimentos sociais" no mínimo indiferentes, ou mesmo hostis, em relação ao movimento operário, em particular às suas principais organizações (o PC e a CGT) e à sua cultura estatizante e autoritária - indiferença e hostilidade, aliás, recíprocas. Cisão que se revelará prejudicial aos dois pólos nessa tensão. E, de fato, em plena expansão no início dos anos 1970, esses movimentos não escapariam ao refluxo generalizado do movimento social que seria causado, no final dessa mesma década, simultaneamente pelo agravamento da crise econômica, o endurecimento da ofensiva capitalista por trás da ideologia liberal, o recuo das lutas proletárias e a impotência global do movimento operário para enfrentar essa nova situação. Os movimentos não chegam a se extinguir, mas a maioria deles entra em declínio, ao mesmo tempo em que continuam fomentando o desenvolvimento de movimentos associativos e de "práticas alternativas".

Nesse intervalo de tempo, porém, os "novos movimentos sociais" produziram dois efeitos duradouros no interior da sociedade francesa. Em primeiro lugar, eles foram um dos elementos motores de uma verdadeira "revolução cultural" (uma revolução em matéria de costumes) pondo em questão os modelos então dominantes em matéria de relações entre homens e mulheres e entre jovens e adultos (pais e filhos, professores e alunos), e conseqüentemente as práticas pedagógicas, as práticas conjugais e familiares, as relações com a sexualidade, as relações com a autoridade e com as instituições em geral, as relações com o trabalho, etc. Em outras palavras, ao longo dos anos 1970, assistiu-se ao desmoronamento de boa parte da "ordem moral", imposta até então pela antiga fórmula hegemônica agora em crise, em proveito do triunfo dos valores éticos apregoados pelo enquadramento; e os "novos movimentos sociais" terão um 
papel decisivo nisso. Nessa mesma medida, serão os vetores de um aggiornamento da sociedade francesa: combatendo suas formas capitalistas arcaicas, e mesmo os elementos pré-capitalistas que ela ainda conservava, eles trabalharão para o seu acabamento capitalista. Por exemplo, combatendo certos aspectos da alienação particular sofrida pelas mulheres como grupo social, exigindo a igualdade de direitos (na família, no trabalho, na sociedade civil, no Estado, etc.) entre homens e mulheres, o movimento feminista contribuiu para estender o campo da alienação geral de que todos os indivíduos, sem distinção de sexo, são vítimas no capitalismo, a começar pelo trabalho assalariado. Sem dúvida, o movimento feminista não se reduziu absolutamente a essa tarefa, o que não impede que esse venha a ser um de seus efeitos mais profundos e mais duradouros.

Em segundo lugar, junto com essa "revolução cultural", esses "novos movimentos sociais" contribuirão para criar as condições para uma reforma institucional de grande amplitude, pondo em jogo as relações do Estado com a sociedade civil assim como a organização interna do aparelho de Estado. De fato, em pouquíssimo tempo, do mesmo modo que as direções capitalistas das empresas conseguiram 'recuperar' (virar a seu favor) certos aspectos e elementos da crítica das formas fordistas de dominação e de exploração do trabalho para desenvolver formas pós-fordistas de organização do processo de produção, os poderes públicos (os dirigentes do Estado nos diferentes níveis de exercício do poder do Estado, em particular nos níveis locais e regionais) procurarão, e conseguirão, 'instrumentalizar' a vontade de reapropriação das condições sociais de existência manifestada e defendida pelos "novos movimentos sociais", confiando-lhes a gestão ou mesmo a organização de certos elementos da sociedade civil, e ao mesmo tempo colocando-os sob sua tutela legal e administrativa e sob sua dependência financeira. Das creches familiares para suprir a insuficiência das creches públicas em matéria de acolhimento da pequena infância aos comitês de bairro para a elaboração de planos de urbanização ou de transportes coletivos em ligação com os serviços municipais, os poderes públicos, apresentando-se como os porta-vozes dos habitantes, encontraram entre os atores dos "novos movimentos sociais", "parceiros responsáveis" que thes forneciam elementos quase sempre originais para a solução de problemas sociais crônicos que os haviam desafiado até então.

Assim, essa estreita colaboração entre "novos movimentos sociais" e poderes públicos locais e regionais na gestão da sociedade civil fez parte de uma reestruturação do aparelho de Estado, que se tornara necessária na França assim como em outras formações centrais, pela super-acumulação na esfera do Estado de 
tarefas administrativas ao longo do período fordista, segundo sua própria lógica, e depois, rapidamente, a partir do início dos anos 1980, pelas exigências próprias à transnacionalização do capital. Como já tive oportunidade de mostrar em outra parte, isso implica de fato um desdobramento do aparelho de Estado, obrigando-o a se desincumbir em suas instâncias locais e regionais das tarefas subalternas de regulação social e, principalmente, de toda a gestão da reprodução da força social de trabalho ${ }^{8}$.

E, como se pode imaginar, graças a essa reforma institucional, que implicava sobretudo a colaboração entre "novos movimentos sociais" e poderes públicos locais e regionais, certos membros do enquadramento conseguirão satisfazer sua ambição política convertendo-se de militantes contestadores ou de animadores de "práticas alternativas" em novos notáveis locais. Com isso, os "novos movimentos sociais" permitirão ao enquadramento não apenas fazer prevalecer no espaço público alguns de seus valores éticos, mas também (pelo menos no que diz respeito a uma minoria de seus membros) desempenhar finalmente um papel político e ocupar posições institucionais proporcional ao seu peso socioeconômico.

3. Para coroar seu empenho de sair da marginalidade política em que se encontrava antes, o enquadramento precisava ainda dispor de um aparelho político apropriado que lhe permitisse sonhar em ver um dia seus representantes ascenderem ao exercício do poder de Estado. A formação desse aparelho e sua marcha rumo ao poder constituirão o terceiro e último momento de sua mobilização geral ao longo dos anos 1970.

0 primeiro momento dessa marcha rumo ao poder consiste na refundação da esquerda não "comunista" que ocorre no final dos anos 1960. Sob a direção de Guy Mollet, incapaz de dimensionar as transformações em curso na sociedade francesa, a velha SFIO foi enfraquecendo cada vez mais ao longo da década, perdendo filiados e votos nas eleições. Chega ao fundo do poço na eleição presidencial de junho de 1969, quando seu candidato (Gaston Defferre) obtém apenas 5\% dos sufrágios, muito atrás do candidato do PC, Jacques Duclos (21,5\%). Já no mês seguinte é realizado um congresso extraordinário no qual a SFIO se dissolve para renascer com o nome de Novo Partido Socialista, logo chamado de Partido Socialista (PS), englobando diversos agrupamentos fora da

${ }^{8}$ Tratei disso principalmente em Bihr (1991, capítulo VI; e 2000). 
SFIO, comandado por Alain Savary que empreende a renovação da "velha casa" "socialista". Esta culminará, principalmente, no congresso de Epinay (junho de 1971), com a integração ao PS da Convenção das Instituições Republicanas de François Mitterrand, que se torna também o novo secretário geral do partido. Em 1965, ele já tinha sido o candidato único da esquerda à primeira eleição presidencial por sufrágio universal, conseguindo levar a disputa com o general de Gaulle ao segundo turno, quando totalizou $45 \%$ dos votos.

0 ano seguinte (1972) assiste à consolidação de uma aliança política entre 0 PS e o PC, a União da Esquerda (UG), visando conquistar a maioria no Parlamento e assumir responsabilidades governamentais. Logo se somarão a eles, pela ala esquerda, o que restou do antigo Partido Radical (os "radicais de esquerda"). Assim, pela segunda vez desde o congresso de Tours (1920), que presenciou a divisão da SFI0 entre irmãos inimigos "comunistas" e "socialistas", e trinta e seis anos depois da efêmera experiência da Frente Popular (1936-1937), assiste-se à formação de uma aliança entre o conjunto dos partidos de esquerda. É evidente que essa aliança não teria existido sem a dupla mobilização do proletariado e do enquadramento, ainda em plena dinâmica ascendente na época: é sob a pressão dessa mobilização que ela se consolida. Mas é evidente também que, desde o início, ela expressa as ambigüidades e as contradições internas.

Estas se encontram antes de tudo na composição sociológica dos dois principais protagonistas dessa aliança. A base social (os eleitores, os filiados, os militantes) do PC e a do PS é recrutada conjuntamente dentro do proletariado e do enquadramento, mas em proporções muito diferentes: o proletariado é predominante na base do PC, enquanto a do novo PS é logo dominada por uma maioria de membros do enquadramento. Além disso, mesmo dentro de cada uma dessas classes, não são sempre as mesmas camadas e categorias que estão envolvidas: a base proletária do PC é essencialmente operária, enquanto a do PS congrega mais empregados; os elementos do enquadramento que o PC mobiliza são quase exclusivamente técnicos e engenheiros da indústria e uma parte de professores (primários e secundários), enquanto que o PS recruta de forma bem mais ampla no conjunto da classe do enquadramento, inclusive, e sobretudo, nos setores externos à indústria.

0 contraste entre as duas formações se acentua ainda mais quando se examina a composição sociológica de seus respectivos aparelhos (os eleitos, os responsáveis pelas federações, os permanentes, as instâncias dirigentes). 0 do PC é composto amplamente de antigos proletários (sobretudo operários de ofícios ou 
operários profissionais, mas que em razão disso tinham mudado seu pertencimento de classe nesse meio tempo); já o do PS é composto esmagadoramente de membros do enquadramento (sobretudo de sua fração pública, a grande maioria de professores); mas inclui também membros das profissões liberais e mesmo membros oriundos da burguesia.

Assim, embora globalmente a aliança entre PC e PS constitua a armadura de um bloco social englobando parcelas inteiras do enquadramento e do proletariado, é evidente que a relação de forças entre essas duas classes, e portanto a hegemonia na UG, se decidirá no braço de ferro que continua a opor as duas formações por trás da fachada da "união da esquerda". Pois "a união é um combate", segundo uma frase que será muito utilizada nesses anos.

Esse braço de ferro se expressará principalmente no nível das orientações programáticas da aliança. De fato, a união se realiza inicialmente em torno de um programa político, o famoso "Programa comum de governo". Por trás de uma fraseologia revolucionária (como "ruptura com o capitalismo") e de um palavreado marxizante (fala-se de "lutas de classe") destinados a seduzir ou a ludibriar os elementos radicalizados da base social das duas formações, trata-se na verdade de um programa reformista clássico visando arrematar a construção do fordismo na França. Nessa mesma medida, ele tem assim, na origem, a marca do PC, mais do que PS - e se encontra aqui aquilo que já tive oportunidade de dizer anteriormente sobre o papel desempenhado pelo PC e pela CGT como protagonistas do compromisso fordista na França. Mas isso significa também que, à primeira vista, se está diante de um programa situado na perspectiva da confirmação de um compromisso entre o bloco social proletariado-enquadramento (grosso modo, o mundo salarial) com a classe dominante, a despeito de alguns elementos, acentos e referências próprias para assustar esta última.

Contudo, à medida que se avança na década de 1970, as orientações programáticas da UG sofrerão inflexões. De um lado, com a ruptura na longa dinâmica de crescimento do regime fordista de reprodução instaurada pelo primeiro "choque do petróleo", certos dirigentes socialistas começam a ter dúvidas sobre a oportunidade ou simplesmente a eficácia do "programa comum" em face da nova situação econômica (embora ainda não se compreenda bem sua natureza). Sem dúvida, eles contam sempre com as receitas keynesianas clássicas (aumento de salários diretos e indiretos, criação de empregos no setor público, lançamento de alguns grandes obras públicas, redução do tempo de trabalho semanal para 35 horas, diminuição da idade de aposentadoria para 60 anos) para 
sair da estagflação; mas, sob o pretexto da "atualização do programa comum", eles pedem que seja revista para baixo a ambiciosa lista de nacionalizações de indústrias e bancos previstas inicialmente por esse programa. A recusa oposta pelo PC a tal revisão levará à ruptura da UG no outono de 1977, o que fará com que esta última perca as eleições legislativas da primavera seguinte que ela tinha sérias chances de ganhar, considerada sua progressão eleitoral constante desde 1973.

Por outro lado, no interior do próprio PS, a partir de meado da década, assiste-se à escalada de uma corrente autodenominada "segunda esquerda", que se nutria de referências à autogestão, aos "novos movimentos sociais", às "práticas alternativas" e à "experimentação social", tomando partido da "sociedade civil" contra o Estado, hostil ao estatismo que supostamente caracterizava o antigo movimento operário, tanto em sua versão social-democrata quanto em sua versão stalinista. Essa corrente é reforçada pela adesão ao PS de boa parte do PSU no outono de 1974 seguindo Michel Rocard. E encontra respaldo e apoio também dentro da CFDT $^{9}$ que, desde 1976, sob o impulso de Edmond Maire, se distancia da UG e prepara a guinada à direita de sua organização que começará com a "recentragem" votada durante seu congresso de 1978. E, evidentemente, esse conjunto de forças apóia a direção do PS em seu braço de ferro com o PC, do mesmo modo que prepara a recepção, por uma parte das elites políticas de esquerda, ao longo desses mesmos anos, do discurso "antitotalitário" elaborado pelos autodenominados "novos filósofos" (Bernard-Henri Lévy e André Glucksmann são os mais conhecidos), que em poucos anos passaram "do colarinho Mao ao Rotary" segundo a feliz expressão irônica de Guy Hocquenghem, a fim de vacinar definitivamente a esquerda contra o marxismo.

No final da década, a partida de braço de ferro entre PC e PS vira manifestamente em favor deste último. No plano eleitoral, em menos de dez anos, ele conseguiu alcançar e ultrapassar o PC; e, no final dos anos 1970, afirma-se claramente como o principal partido de esquerda ${ }^{10}$. Quando o PC se dá conta

${ }^{9}$ N.R.: Confederação Francesa Democrática do Trabalho.

${ }^{10}$ Eis, por exemplo, a evolução da porcentagem de votos obtidos pelo PC e pelo PS (ou afins) no primeiro turno das eleições legislativas entre 1968 e 1981:

\begin{tabular}{|l|l|l|l|l|}
\hline Ano & 1968 & 1973 & 1978 & 1981 \\
\hline PC & 20,0 & 21,4 & 20,6 & 16,1 \\
\hline Esquerda 'socialista' & 16,9 & 21,2 & 26,3 & 38,3 \\
\hline
\end{tabular}

Fonte: http://www.france-politique.fr/resultats-elections-legislatives.htm 
disso e tenta recuperar terreno com a "atualização do programa comum" que conduz à ruptura da UG, já é tarde demais: a desunião da esquerda beneficiará eleitoralmente o PC mais do que sua união. Além disso, desafiando o PC, a equipe dirigente do PS, com Mitterrand à frente, oferece garantias à burguesia e aos seus aliados, que contribuirão para sua vitória eleitoral de maio e junho de 1981.

De fato, a evolução da relação de forças entre PS e PC durante os anos 1970 só contribui para sancionar a diferença de linha política entre as duas formações ao longo da década. Nesta última, o PS se abre a todas as contestações que se desenvolvem na sociedade francesa, tanto do lado das lutas operárias quanto dos "novos movimentos sociais", apropria-se (não sem filtrá-las) de todas as suas temáticas e problemáticas, integra (digerindo-as e moderando-as) todas as novas forças militantes (entre as quais sobretudo membros do enquadramento) que elas revelam - e por isso chegou a ser chamado de "partido arrasta-tudo". Em suma, capitaliza em seu proveito político a aspiração geral, ainda que diversificada e às vezes confusa, à "mudança da sociedade" que se expressa então através da conflitualidade social multiforme ${ }^{11}$.

0 PC, ao contrário, tenderá a se fechar a esse conjunto de elementos novos, a se recolher em suas conquistas (organizacionais e programáticas), como uma cidadela sitiada. Tendo já fracassado a virada da 'desestalinização' no final dos anos 1950, será necessária então uma segunda oportunidade de aggiornamento, quando então será convidado a isso por seus "partidos irmãos", o Partido Comunista Italiano e o Partido Comunista da Espanba, no quadro do "eurocomunismo", que tentará em vão ganhar forma na segunda metade da década. Nada simboliza melhor a esclerose do PC na época que seu secretáriogeral, o inenarrável Georges Marchais, cuja arrogância irônica só se equipara à mediocridade teórica e política. Ousando ainda em 1979 defender a tese do "balanço globalmente positivo" da URSS e de seus satélites da Europa de leste, assim como a legitimidade da intervenção 'soviética' no Afeganistão, ele conduziu o PC, ao longo desses anos, no caminho sem volta de um declínio inelutável.

Mais ainda que na incapacidade do PC de proceder ao seu aggiornamento político, esse declínio inscreve-se então, sem que seus dirigentes tenham consciência disso, como, aliás, a maioria dos observadores da vida social e política francesa,

\footnotetext{
${ }^{11}$ Sintomaticamente, o programa adotado pelo PS no início de 1972 tem como título Mudar a vida, retomando assim uma frase do poeta Rimbaud que tinha ressurgido entre os slogans de maio-junho de 1968.
} 
nas características do novo período do desenvolvimento do capitalismo que está prestes a se abrir graças à crise do regime fordista de acumulação. Isto, de fato, vai pôr em questão todos os pilares sobre os quais o PC tinha sido edificado há décadas e às vezes até desde suas origens: sua base operária, que vai se enfraquecer quantitativamente (em número) e qualitativamente (em combatividade) sob o efeito conjugado das demissões em massa que ocorrerão em certos setores (a siderurgia, os canteiros navais, a indústria automobilística e a metalurgia de maneira mais) a partir do final dos anos 1970 e início dos anos 1980, e da introdução de formas pós-fordistas de organização do trabalho e da produção; sua estratégia nacional-estatista, que fazia do Estado nacional o cenário e a alavanca de qualquer ação política e de qualquer transformação social, cujas capacidades de intervenção serão significativamente reduzidas pela transnacionalização do capital e pelas políticas neoliberais que a acompanham; por último, e em decorrência disso, o compromisso fordista, denunciado pela burguesia que não o deseja mais porque não pode mais pagar seu preço, enquanto que o PC foi aos poucos se integrando inteiramente em seu contexto e em seu jogo institucional, como vimos.

\section{AS BASES (FRÁGEIS) DE UMA NOVA FÓRMULA HEGEMÔNICA}

A esquerda francesa garante, portanto, a maioria parlamentar e a conquista da direção do Estado (a presidência da República) em maio-junho de 1981, treze anos após a eclosão de 1968, em uma conjuntura política muito particular. Sua vitória eleitoral decorreu principalmente das divisões da direita entre gaullistas (comandados por Jacques Chirac) e liberais (agrupados em torno do presidente que saía, Valery Giscard d'Estaing); divisão que não é estranha aos efeitos da ruptura agora consumada da antiga aliança hegemônica entre a grande burguesia e as classes médias tradicionais.

Mas, se a direita está enfraquecida, o mesmo acontece com a esquerda, a despeito de sua vitória eleitoral. E isso, primeiramente, por sua divisão persistente que, no entanto, não a impedirá de governar em conjunto, depois pelo declínio irremediável em que entrou o PC, e por último, e acima de tudo, pelo refluxo das lutas operárias e dos "novos movimentos sociais", perceptível, como vimos, desde o final dos anos 1970. Entretanto, se esse refluxo coloca a esquerda governamental em situação de fraqueza em sua relação de forças com a burguesia, ele lhe confere igualmente maior autonomia em relação à sua própria base social. 
A conjunção dos diversos fatores acima levará ao desfecho do drama político iniciado vinte anos antes. De fato, ela vai permitir a fundação de uma nova aliança hegemônica, não sem mais algumas peripécias. Pois, se graças aos dois mandatos presidenciais de Mitterrand (1981-1995) a esquerda se tornou seu artífice, isso se deu essencialmente devido ao fracasso de seu projeto inicial ${ }^{12}$.

1. Esse projeto, como sabemos, visa restabelecer a dinâmica do regime fordista de reprodução do capital através, por um lado, de uma política de retomada keynesiana clássica, por outro lado, de um programa de nacionalizações de indústrias e bancos. É a essa dupla tarefa que a esquerda, instalada no comando do Estado, se entrega imediatamente.

Na verdade, tal projeto já está anacrônico - o que a maioria de seus autores ignora ou não ousa ainda confessar para os que têm consciência disso. Ele tenta em vão retomar um regime de acumulação do capital que está completamente esgotado; e aposta em um modo de regulação dessa mesma acumulação que pressupõe que a circulação do capital ocorra essencialmente no interior de fronteiras nacionais, ao mesmo tempo em que a internacionalização dessa circulação se estendia e se intensificava sem cessar desde meados dos anos 1960 e que as primeiras ondas de "liberalização" iniciadas pelos governos Thatcher na Inglaterra e de Reagan nos Estados Unidos aceleram brutalmente.

De fato, a implementação pela esquerda de seu programa econômico e social leva-a ao fracasso em poucos meses. Por um lado, sua política de retomada econômica pelo consumo só fez agravar a inflação e aumentar o déficit do comércio exterior, em um contexto de abertura e de interdependência crescentes das economias européias; tanto mais que, simultaneamente, os governos dos outros importantes estados europeus adotaram políticas de austeridade. E, por outro lado, também as nacionalizações de indústrias e bancos logo revelam seus limites: os monopólios nacionais assim constituídos ou projetados não têm evidentemente condições de enfrentar seus concorrentes estrangeiros no mercado mundial; é somente graças a alianças internacionais que eles conseguem agora operar no âmbito desse mercado.

Entretanto, a partir da primavera de 1983, a esquerda governamental, não sem vacilações por parte de alguns de seus membros (do lado do PC, mas

\footnotetext{
${ }^{12}$ Resumirei aqui, essencialmente, a análise que desenvolvi em detalhe em Bihr (1986), mas modificando certas conclusões.
} 
também dentro do PS), faz uma revisão de suas escolhas iniciais e adere a uma política neoliberal, seguindo nesse aspecto o exemplo da totalidade dos governos dos estados centrais (com a exceção notável do Japão na época). Política que implicava o aumento do desemprego, a austeridade salarial (um crescimento dos salários menor que o da produtividade média), uma desregulamentação do mercado de trabalho (o desenvolvimento de várias formas de trabalho precário), a liberalização do mercado de capitais, a privatização de empresas públicas e de uma parte dos serviços públicos, etc. Em síntese, o oposto do que seu programa previa e daquilo que é, mais amplamente, sinônimo de uma política de esquerda. Uma nova orientação que a esquerda assume inicialmente envergonhada sem confessá-lo (o primeiro-ministro Pierre Maurois fala então de umas "simples pausa" nas reformas e de "um parêntese"); depois de maneira cada vez mais resoluta (quando Pierre Maurois for substituído no ano seguinte por Laurent Fabius); antes de adotá-la definitivamente e de fazer dela seu novo credo (isso se efetivará na campanha para as eleições presidenciais e depois legislativas da primavera de 1988 que a reconduz ao poder após a derrota eleitoral de 1986).

Evidentemente, tal política era (e ainda é) perfeitamente ajustada aos interesses e às exigências da parcela mais transnacionalizada da classe dominante, tanto na França como no exterior. Em troca desse ato de vassalagem aos seus interesses imediatos, a esquerda governamental (agora amplamente dominada pelo PS, e este pela "segunda esquerda") ganhará sua confiança duradoura: ela obterá, de sua parte, o reconhecimento de sua capacidade e, mais ainda, de seu direito de "gerir lealmente o capitalismo" segundo a célebre expressão de Léon Blum, podendo desde então rivalizar com a direita nesse terreno.

Mas, de resto, a esquerda precisará convencer sua própriabase social a aceitar essa submissão aos interesses do capital transnacionalizado. No que diz respeito ao enquadramento, ela conseguirá, pelo menos em parte, oferecendo a algumas dessas camadas e categorias, à guisa de compensação, oportunidades de satisfazer suas ambições de poder: prebendas e sinecuras na sociedade política (os aparelhos de Estado) ou na sociedade civil (os movimentos associativos). A remodelagem do aparelho de Estado, engendrada por leis de descentralização (1982-1983), criará inúmeras oportunidades dessa natureza. Assim emergiu uma nova geração de "notáveis rosas", oriundos do enquadramento, ocupando postos e assentos da base ao cume desse novo dispositivo de poder, em particular na articulação entre poderes locais fortalecidos e movimentos associativos promovidos a parceiros desses poderes na gestão de diversos equipamentos coletivos e de serviços públicos. 
Em suma, uma sistematização do dispositivo que começara a ser implantada nos anos 1970 .

Será preciso, finalmente, chamar à ordem o proletariado. E é justamente nisso que a esquerda governamental se empenhará durante os dois mandatos de Mitterrand. Ao longo da década de 1980, ela saberá empreender a tarefa de questionamento das conquistas do período fordista com mais determinação que a direita ousara fazer até então manifestar. Foi ela, por exemplo, que impôs e obteve a aceitação, por intermédio e com a ajuda de organizações sindicais, de uma política de austeridade salarial, sinônimo de uma queda programada do nível de vida (pondo fim à indexação dos salários aos preços), o que a direita tinha adiado durante anos temendo o enfrentamento que isso poderia causar com o proletariado e, mais amplamente, com o mundo assalariado. Foi ela também que começou a reduzir a extensão dos direitos à proteção social (contra a doença, contra o desemprego) e a tornar mais rígidas as condições de acesso. E foi ela que conseguiu ainda erodir a capacidade conflituosa do proletariado, já sensivelmente enfraquecida quando de sua chegada ao poder, impedindo as greves operárias de 1983 e 1984 nos setores em reestruturação (mineração, siderurgia, canteiros navais, automobilístico), mas também, simplesmente, pelo aumento do desemprego e da precariedade. Com isso, revelou-se especialista na arte de enfraquecer de forma duradoura o movimento operário, principalmente pela maior integração de suas organizações sindicais ao aparelho de Estado e pelo compromisso com as ofensivas contra sua própria base. Mais do que isso, ela não chegou inclusive a transformar parte desse movimento em defensor convicto de sua política neoliberal? Recordese aqui da guinada direitista da CFDT, que em alguns anos passou da luta pelo "socialismo autogestionário" à exaltação das virtudes da "economia de mercado", e seu secretário-geral (Edmond Maire) chegou a qualificar a greve de "arcaísmo". Em suma, a esquerda governamental e seus apoios sindicais favoreceram com isso o salve-se-quem-puder geral dentro do proletariado, o retraimento nos reflexos corporativistas e nas práticas individualistas. Retraimento propício à interiorização da idéia de que "Não bá outra política possível" e de que "Com a direita seria pior ainda!", mascarando assim o fato de que a esquerda se torna nesse período uma segunda direita.

2. Assim, ao longo dos anos 1980, a esquerda governamental, com o PS à frente, conseguiu criar as condições para o consentimento da ampla maioria do "povo de esquerda" (enquadramento e proletariado) às orientações de sua 
política neoliberal e da política neoliberal - seja ela comandada pela esquerda ou pela direita. Uma política dócil aos interesses e exigências de um grande capital amplamente transnacionalizado, que se limita apenas a atenuar certas conseqüências dele no plano social.

Consentimento passivo no essencial, como diria Gramsci. Pois é feito sobretudo de resignação à ordem existente de diversos modos: de satisfação de ambições medíocres para uns, de esperanças frustradas e de ilusões perdidas para outros, de renúncia e de desencorajamento para outros ainda, de despolitização, enfim, para um número crescente, levando ao agravamento do absenteísmo eleitoral e mesmo à não inscrição nas listas eleitorais, de que a própria esquerda pode ter sido vítima na época ( $c f$. o que se passou quando das eleições presidenciais e legislativas da primavera de 2002). Resignação que vem reforçar a incapacidade de criar uma verdadeira alternativa política à esquerda da esquerda governamental, e isso a despeito do desenvolvimento do altermundialismo (em particular na e em torno da associação ATTAC e da Fondation Copernic) e da persistência de uma polarização de parte da base social da esquerda por formações de extrema esquerda. Por isso, é também um consentimento frágil e precário. Não exclui a retomada pontual da conflitualidade popular, como se viu em vários momentos: quando dos movimentos grevistas de enfermeiras, professores primários, agentes do fisco em 1987-1988, quando do grande movimento grevista de novembro-dezembro de 1995 contra a "reforma" do seguro doença, quando dos movimentos grevistas da primavera de 2003 contra a "reforma" do seguro velhice cuja dinâmica criou as condições de uma greve geral, também nesse caso torpedeada pelas direções sindicais.

Mas é igualmente um consentimento que cria ao mesmo tempo espaço suficiente para a fundação de um novo bloco hegemônico, sustentado na aliança do grande capital transnacional com as categorias superiores do enquadramento, e que encontra respaldo e apoio no grosso do enquadramento e em certas camadas do proletariado, e na qual o enquadramento ocupa globalmente o lugar reservado às classes médias tradicionais na antiga fórmula hegemônica. É sobre esse bloco que repousa agora a hegemonia da classe dominante na França, como aliás na maioria dos estados centrais (pelo menos na Europa).

É principalmente nesse bloco (nas relações de força entre esses diversos elementos constitutivos) que se apóia a alternância no poder, há vinte anos, de coalizões governamentais de direita e coalizões governamentais de esquerda. 
Coalizões com orientações políticas fundamentalmente comuns, voltadas à gestão neoliberal da inserção da economia e da sociedade francesas no mercado mundial (e, sobretudo, na União Européia), segundo os interesses da fração transnacionalizada do capital. Coalizões que já não diferem muito entre elas a não ser quanto ao ritmo em que se deseja proceder às "reformas" necessárias para esse fim, e quanto às compensações que se deseja acrescentar a essas reformas para torná-las menos dolorosas para as classes populares.

Essa alternância traduz ao mesmo tempo a fragilidade relativa desse novo bloco hegemônico, pelo fato de que ele repousa apenas sobre o consentimento passivo de boa parte de sua base social e de que a coesão entre esses diferentes elementos constitutivos ainda é imperfeita. Mas, paradoxalmente, essa alternância garante também a força desse bloco, sua capacidade de perdurar e de se renovar, pois sempre oferece uma solução governamental de reposição do desgaste que implica inevitavelmente o exercício do poder, tanto mais quando a política praticada só pode ser impopular.

\section{Conclusão}

Escrever a história de um ciclo de lutas sociais, políticas e culturais quase meio século depois que elas ocorreram apresenta inevitavelmente o risco de ceder à tentação de considerá-las apenas do ângulo daquilo que elas acabaram por trazer, dos resultados históricos que acabaram por produzir. Saber como a história terminou, pelo menos provisoriamente, apresenta evidentemente a vantagem de poder ordenar segundo seu fim, arriscando ao mesmo tempo fazer desse fim uma finalidade imanente, um telos para o qual ela seria inevitavelmente orientada, à revelia de seus atores, fazendo assim das ações destes últimos uma simples astúcia da História e de suas representações de ilusões ou mesmo fantasias que o historiador pode então tratar, conforme os casos, com um desdém irônico ou com uma piedade benevolente. Com o risco de não compreender, como penso ter mostrado, que essas ilusões comportavam também uma parte de verdade, ligadas a possibilidades não advindas, mas efetivas.

Espero ter conseguido, neste artigo, evitar esse grande perigo mostrando que essa história foi a história de lutas de classes, com tudo aquilo que elas comportam necessariamente de indeterminação a priori - pois seu resultado depende sempre da evolução das relações de forças que nenhum dos protagonistas pode controlar ou prever. Se, em tal história, nem tudo é possível, nada jamais 
está escrito de antemão. Assim, não era necessário que essa história terminasse como (provisoriamente) terminou. Na França, como em toda parte, a História continua.

Podem me criticar, em segundo lugar, por ter de algum modo, ao procurar situar a grande crise política que a França conheceu em maio-junho de 1968 em sua longa história social, reduzido inevitavelmente sua amplitude - da mesma maneira que um pico montanhoso parece menos alto e tende progressivamente a se fundir na paisagem à medida que se afasta dele ou que se eleva para captar com o olhar um campo geográfico mais vasto. Espero, ao contrário, ter mostrado que, ao olhar da longa história da formação social francesa, a crise de maio-junho de 1968 foi um acontecimento muito importante, comparável apenas à Comuna de Paris. Aliás, é exatamente esse o sentido de minha demonstração: com quase um século de distância, os dois acontecimentos foram os pontos de partida de um ciclo hegemônico. Esperemos simplesmente que o que se iniciou com maio-junho de 1968 seja menos longo que o anterior a que eles puseram fim!

Uma terceira crítica que podem me dirigir é por ter tratado separadamente as duas faces de maio-junho de 1968 e de seus desdobramentos: o ciclo de lutas operárias, o movimento estudantil e os "novos movimentos sociais", embora fossem inseparáveis e tenham se nutrido mutuamente. Neste caso, a crítica se justifica em parte. Contudo, além de ter tido o cuidado de mencionar a articulação entre essas duas faces do movimento, seu tratamento diferido, mais do que separado, era necessário à clareza de minha exposição analítica dos diferentes atores e momentos do processo sociopolítico particularmente complexo que se desenvolve, grosso modo, entre 1968 e 1981. Complexidade que, de resto, não pretendo ter esgotado com minha análise.

Finalmente, última crítica que este artigo pode suscitar, minha análise da crise de maio-junho de 1968 ficou fechada em uma perspectiva muito francofrancesa, embora essa crise tenha feito parte de um movimento mais geral de contestação do mundo então existente, que ultrapassou amplamente as fronteiras da França. Contudo, eu poderia argumentar que, de um lado, em nenhum lugar (salvo sem dúvida a Itália), esse movimento geral de contestação foi tão potente e radical quanto na França; e que, de outro lado, tive o cuidado de começar recordando o contexto internacional geral em que ele se desenrolou na França. Mas eu aceitaria sem vacilar que essas poucas observações são muito insuficientes, e que ainda resta por ser escrita uma história conjunta desse período, desse ciclo 
internacional de lutas de classes que foi também um ciclo de lutas internacionais, de lutas entre Estados-nações, lutas ao mesmo tempo interimperialistas e antiimperialistas.

\section{REFERÊNCIAS}

BIHR, Alain. Entre bourgeoisie et prolétariat: l'encadrement capitaliste. Paris: L'Harmattan, 1989.

. Du 'Grand Soir' à l'alternative. Paris: Ed. Ouvrières/Editions de l'Atelier, 1991. [Tradução no Brasil: Da Grande Noite à alternativa. São Paulo: Boitempo Editorial, 1998].

GAURON, André. Histoire économique et sociale de la Ve République. Paris: La Découverte, tome 1, Le Temps des Modernistes, 1983.

GRAMSCI, Antonio.Cahiers de prison, $n^{\circ} 6$ [1930-1933]. Paris: Gallimard, 1983. [Tradução no Brasil: Cadernos do cárcere. Rio de Janeiro: Civilização Brasileira, 2000-2002, 6 vols].

LA BOÉTIE, Etienne de. Discours de la servitude volontaire ou le Contr'un [1548]. Paris: Flammarion, 1993.

PORTELLI, Hugues. Gramsci et le bloc historique. Paris: PUF, 1972. [Tradução no Brasil: Gramsci e o bloco bistórico. Rio de Janeiro: Paz e Terra, 1977].

POULANTZAS, Nicos. Pouvoir politique et classes sociales. Paris: Maspero, 1971, tomo 2. [Tradução no Brasil: Poder político e classes sociais. São Paulo: Martins Fontes, 1986]. 